\title{
Significando ações através da afetividade
}

\author{
Significando acciones a través de la afetividad
}

\author{
Meaning actions through the affectiveness
}

\author{
Ana Luísa Antunes Rezende Tolfo ${ }^{1}$ \\ Silvana Maria Gritti
}

\begin{abstract}
Resumo
O presente trabalho foi desenvolvido na Escola Municipal de Educação Básica Fernando Ferrari, em uma turma de segundo ano do ensino fundamental, com aluno incluído, objetivando-se o real envolvimento dos educandos na dinâmica escolar através dos laços de afetividade; e auxiliar no desenvolvimento de ações que solidarizem as boas relações com respeito, amizade, confiança, carinho, responsabilidade entre outras. A cada início de ano letivo principiam-se novos encontros, novos conhecimentos, novos olhares, novas relações e novos caminhos a se estabelecer. A princípio de que desenvolvemo-nos como sujeitos sociais a partir das relações e logo, da qualidade destas relações, a escola como espaço formador acaba por proporcionar diferentes experiências de comportamento, emoção, frustrações e conquistas. Quando a criança inicia a escola, demonstra grande expectativa com o que e quem irá encontrar no novo ambiente (sala de aula, merenda, pátio, colegas, professor, etc), assim é essencial que sua percepção seja positiva, estabelecendo vínculos e relações que irão auxiliar no desenvolvimento do processo educativo. De acordo com Vygotsky (2003), "A experiência e a pesquisa têm demonstrado que um fato impregnado de emoção é recordado de forma mais sólida, firme e prolongada que um feito indiferente." Visando consolidar relações de qualidade, busca-se estabelecer vínculos com e entre os educandos de respeito, confiança, amizade e solidariedade, através de propostas que valorizem tais ações.
\end{abstract}

Palavras-chave: Afetividade. Escola. Relações de qualidade.

\section{Resumen}

El presente trabajo fue desarrollado en la Escuela Municipal de Educación Básica Fernando Ferrari, en una clase de segundo año de la enseñanza fundamental, con alumno incluido, objetivándose el real involucramiento de los educandos en la dinámica escolar a través de los lazos de afectividad; y ayudar en el desarrollo de acciones que solidaricen las buenas relaciones con respecto, amistad, confianza, cariño, responsabilidad entre otras. A cada inicio de año lectivo se empiezan nuevos encuentros, nuevos conocimientos, nuevas miradas, nuevas relaciones y nuevos caminos a establecerse. Al principio de que nos desarrollamos como sujetos sociales a partir de las relaciones y luego, de la calidad de estas relaciones, la escuela como espacio formador acaba por proporcionar diferentes experiencias de comportamiento, emoción, frustraciones y conquistas. Cuando el niño inicia la escuela, demuestra una gran expectativa con lo que y quién se encontrará en el nuevo ambiente (aula, merienda, patio, colegas, profesor, etc), así que es esencial que su percepción sea positiva, estableciendo vínculos y relaciones que en el desarrollo del proceso educativo. "La experiencia y la investigación han demostrado que un hecho impregnado de emoción es recordado de forma más sólida, firme y prolongada que un hecho indiferente." Para consolidar relaciones de calidad, se busca establecer vínculos con la sociedad y entre los educandos de respeto, confianza, amistad y solidaridad, a través de propuestas que valoren tales acciones.

Palabras clave: Afectividad. Escuela. Relaciones de calidad.

\footnotetext{
${ }^{1}$ Mestranda em Educação, UNIPAMPA; Jaguarão; RS; Brasil; aninha.tolfo@ hotmail.com

${ }^{2}$ Doutora em Educação pelo Programa de Pós-Graduação em Educação da Universidade Federal do Rio Grande do Sul- UFRGS; RS; Brasil; silvanagritti@gmail.com
} 


\begin{abstract}
The present work was developed in the Fernando Ferrari School of Basic Education, in a second year class of elementary school, with a student included, aiming at the real involvement of the students in the school dynamics through the bonds of affectivity; and assist in the development of actions that foster good relations with respect, friendship, trust, affection, responsibility and others. Each new school year begins new meetings, new knowledge, new looks, new relationships and new paths to be established. At the outset that we develop as social subjects out of relationships and therefore, the quality of these relationships, the school as a formative space ends up providing different experiences of behavior, emotion, frustrations and achievements. When the child starts school, he shows great expectations about what and who will find in the new environment (classroom, lunch, patio, classmates, teacher, etc.), so it is essential that his perception is positive, establishing bonds and relationships that will assist in the development of the educational process. According to Vygotsky (2003), "Experience and research have shown that an emotion-filled fact is remembered more solidly, firmly and protracted than an indifferent feat." In order to consolidate quality relationships, it seeks to establish links with and among the students of respect, trust, friendship and solidarity, through proposals that value such actions.
\end{abstract}

Keywords: Affectivity. School. Quality relationships.

\title{
1. Introdução
}

Desde o nascimento, todo indivíduo tem a necessidade de afeto e atenção para desenvolver-se em um processo harmônico de integração familiar e consequentemente social. A princípio de que desenvolvemo-nos como sujeitos sociais a partir das relações e logo, da qualidade destas relações, a escola como espaço formador acaba por proporcionar diferentes experiências de comportamento, emoção, frustrações e conquistas.

Observa-se a educação como uma ação presente em qualquer sociedade, é o ensinar e aprender, os modos culturais de ser e agir. Ocorre no cotidiano, na escola, na informalidade e em diferentes espaços. Deve-se educar, de acordo com Paro (1997) com diálogos abertos, com informações que provoquem reflexões a respeito dos fatos sociais existentes.

As reações emocionais exercem uma influência essencial e absoluta em todas as formas de nosso comportamento e em todos os momentos do processo educativo. Se quisermos que os alunos recordem melhor ou exercitem mais seu pensamento, devemos fazer com que essas atividades sejam emocionalmente estimuladas.

É importante que se trabalhe sempre com o concreto, assim o educando se sentirá estimulado a criar situações como todo o processo democrático, que é um caminho que se faz ao caminhar, o que não elimina a necessidade de refletir previamente a respeito dos obstáculos e potencialidades que a realidade apresenta para a ação.

A experiência e a pesquisa têm demonstrado que um fato impregnado de emoção é recordado de forma mais sólida, firme e prolongada que um feito indiferente. (VYGOTSKY, 2003) Quando a criança inicia a escola, demonstra grande expectativa com o que e quem irá encontrar no novo ambiente (sala de aula, merenda, pátio, colegas, professor, etc), assim é 
essencial que sua percepção seja positiva, estabelecendo vínculos e relações que irão auxiliar no desenvolvimento do processo educativo.

Assim, a escola tem seu significado validado a partir do momento que o ensino é significativo. E pra que se ocorra uma aprendizagem significativa se faz necessário trabalhar com o potencial significativo que se tem em aula, ou seja, levar em consideração o que a criança já tem conhecimento, o que lhe chama a atenção e suas opiniões.

A construção do conhecimento pela criança se dá com o processo educativo que se preocupa em valorizar a atividade da criança e cabe então ao professor compreender os mecanismos de aprendizagem em consonância com as teorias do conhecimento.

É importante entender que o processo de construção do conhecimento pode ser realizado por meio de jogos e estratégias, que possibilitem o desenvolvimento do raciocínio, permitindo que a criança envolva-se com o levantamento de hipóteses e conjecturas, aspectos fundamentais ao desenvolvimento do pensamento cientifico que mostrará a diferença visual em função da estruturação mental entre os objetos, ou seja, a criança progride na construção do conhecimento, principalmente pela coordenação das relações simples.

\section{Significando ações através da afetividade}

Para o professor é importante que se saiba como ocorre o desenvolvimento psicológico quanto as aprendizagens, pois ele lida com indivíduos que estão construindo as estruturas intelectuais além dele estar contribuindo para a formação do mesmo.

O professor, então, ao estar lidando com esses indivíduos, deve entender como ocorre esse processo, das etapas iniciais até a final, que ocorre na vida adulta, para isso é necessário estudar o desenvolvimento desde seu início.

Ao nascer a criança precisa da ajuda dos adultos para sobreviver, e, é através de seus reflexos que ela se comunica com eles. Nesse processo alguns dos reflexos são importantes futuramente, pois dão lugar a desenvolvimentos muito complexos; e outros tem uma influência muito pequena para o desenvolvimento psicológico posterior.

Para entender como se produz o desenvolvimento deve-se buscar compreender como ocorre a adaptação do indivíduo ao meio, assim como os que ele passa.

Segundo Kamii (2003, p.14)

"Piaget estabeleceu uma distinção fundamental entre três tipos de conhecimento considerando suas fontes básicas e seu modo de estruturação: o conhecimento físico, o conhecimento lógico-matemático e o conhecimento social”. 
O conhecimento físico é o conhecimento externo de qualquer objeto ou coisa que mostra a realidade através do seu aspecto físico, mostrando a diferença entre um objeto e outro, ou seja o aluno retira as informações dos objetos.

Já o conhecimento lógico-matemático mostra a diferença visual em função da observação mental entre os objetos, ou seja, a criança progride na construção do conhecimento principalmente pela coordenação das relações simples.

Para que a criança adquira o conhecimento social é indispensável a interferência de outras pessoas, mas isso não significa que seja suficiente para a criança adquirir o conhecimento social.

Assim como o conhecimento físico, o conhecimento social é um conhecimento de conteúdo e requer um estrutura lógico-matemática para sua assimilação e organização, onde essa mesma estrutura é usada pela criança para construir tanto o conhecimento físico quanto o social.

Neste sentido, pode-se afirmar que a estrutura lógico-matemática não pode ser ensinada diretamente, uma vez que a criança tem que construí-la por si mesma. Mas o professor deve fazer algo como encorajar a criança a pensar ativamente (colocar coisas em relações), estimulando desta forma, o desenvolvimento desta estrutura mental.

Ao ressaltar o papel determinante da atividade da criança na aprendizagem, define-se a escola como um ambiente que deve estimular e favorecer esse processo de autoconstrução.

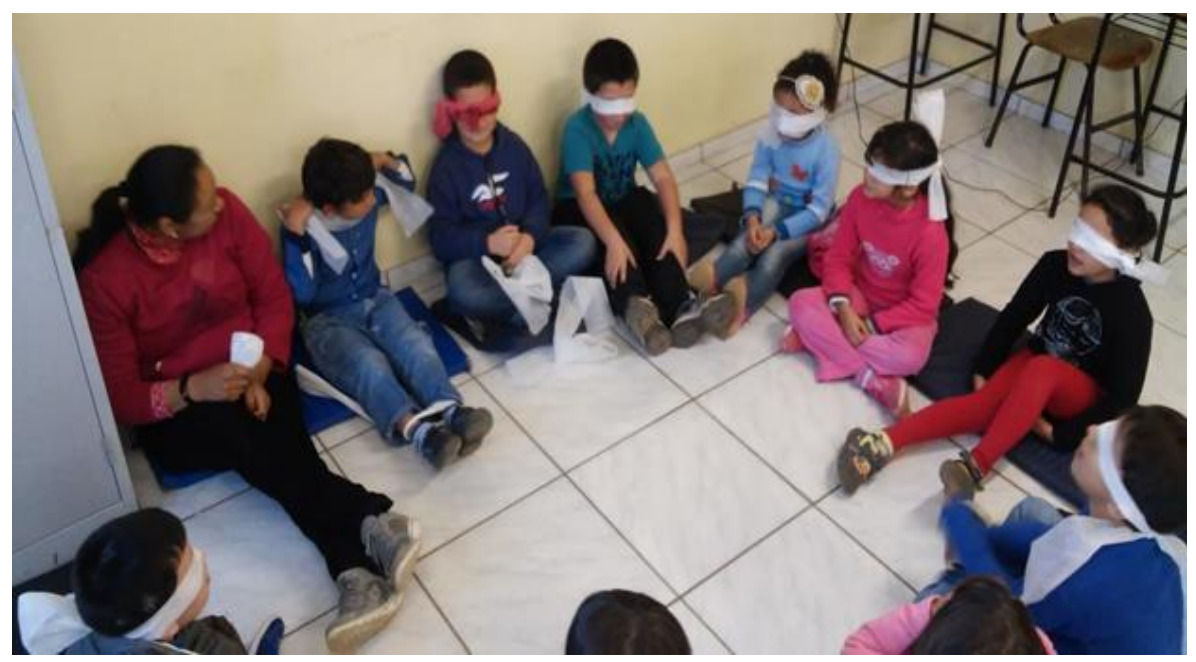

Fotografia 1 - Professora Jocelene e sua turma em atividade sobre os sentidos

Ao início de cada ano letivo propõem-se diferentes desafios em cada escola, em cada sala de aula, para cada profissional em educação. Principiam-se novos encontros, novos conhecimentos, novas relações e novos caminhos a se estabelecer. $\mathrm{Na}$ tentativa de estimular a aprendizagem dos educandos e visando consolidar relações de qualidade, busca-se estabelecer vínculos com e entre os educandos de respeito, confiança, amizade e solidariedade, através de 
propostas que valorizem tais ações. Logo, deparamo-nos com a dificuldade em ter-se um significado a atividade de aprender, pois dentre os alunos da turma, nem todos compartilham do gosto pelo ler, escrever e desenvolver as propostas, sem que haja uma função muito significativa, uma verdadeira conquista para desenvolver tais ações.

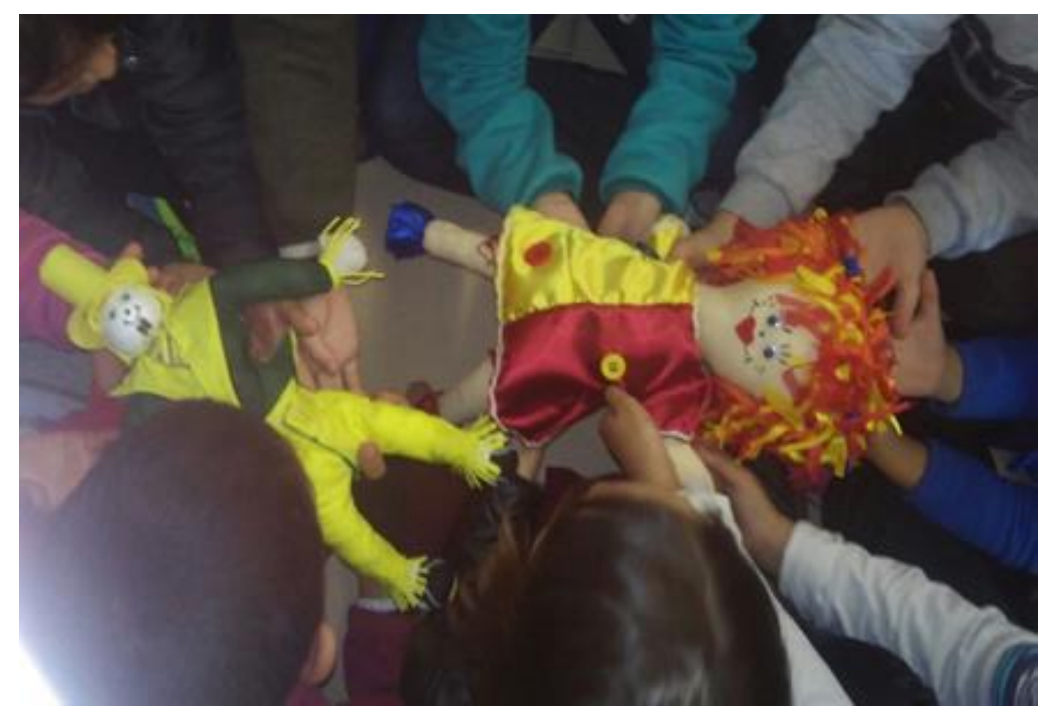

Fotografia 2 - Personagens de algumas das histórias trabalhadas

Assim, primeiramente buscou-se sondar o repertório de interesse dos alunos e a partir daí elaborar propostas que contemplem o significar da aprendizagem. O universo do trabalho baseia-se principalmente no desenvolvimento de atividades em função das histórias infantis, com ênfase até então na Branca de Neve e os Sete Anões e Sítio do Pica-pau Amarelo. Desenvolveu-se atividades de leitura, encenação, reescrita, canto, paródia e vídeo das histórias, construção dos personagens em diferentes materiais (papel, tecido, sabugo, massa de modelar, argila, etc).

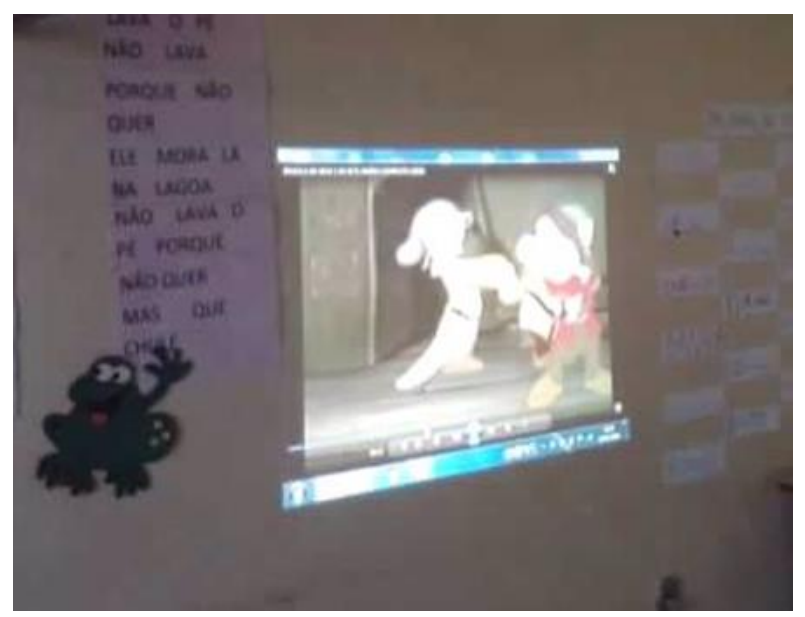

Fotografia 3 - Vídeo de uma das histórias trabalhadas

Realizou-se um paralelo entre o que gosto e o que não gosto; a escrita do significado 
da escola no seu crescimento (intelectual e social); e a construção de regras de convivência com o grupo, após estas reflexões escolheu-se o nome da turma e o nome do mascote da turma (um grande urso com um grande coração), após algumas semanas significando estas ações e deixando tempo para os primeiros laços se firmarem, o coração começou a viajar, ou seja, o mascote da turma emprestava o seu grande coração para um integrante da turma leválo pra casa, compartilha-lo com seus familiares e principalmente cuidar do seu presente.

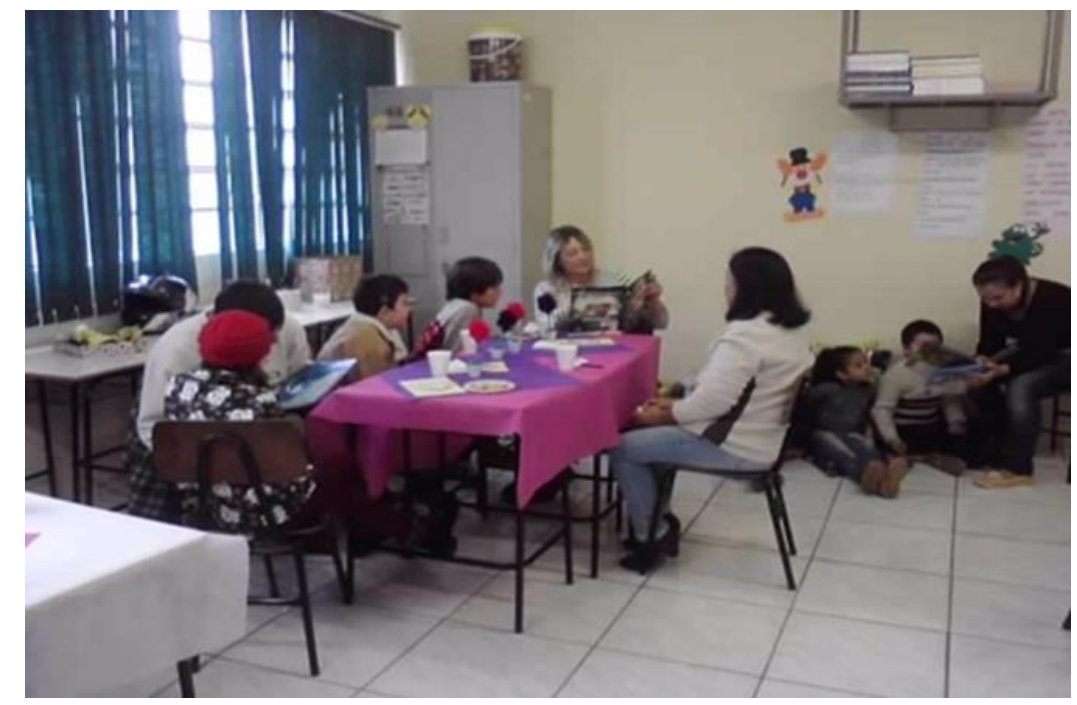

Fotografia 4 - Participação das famílias em atividades

$\mathrm{Na}$ próxima aula o aluno socializava com os colegas o dia e seus cuidados com o coração, escolhendo um amigo para passar a responsabilidade dos cuidados do coração.

Realizou-se atividades simples, mas que conseguissem estabelecer de certa forma um vínculo com os alunos.

Como afirma Mussen (1970) as crianças não só mudam com a idade, mas em qualquer idade, também revelam acentuadas diferenças individuais em muitos aspectos do desenvolvimento.

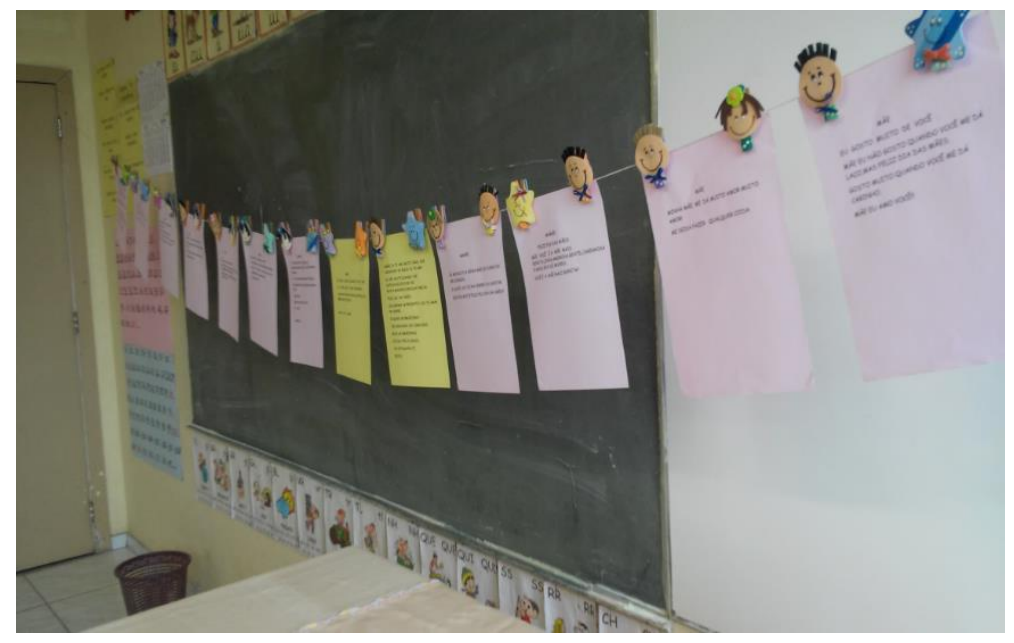

Fotografia 5 - Produções dos alunos 


\section{Conclusões}

Após algumas semanas observou-se que a dinâmica do grupo propunha em compartilhar não só seus saberes, mas suas emoções e a solidariedade dos colegas em acolher aquele que estivesse se sentindo inseguro ou triste, e envolver-se nas construções da turma de maneira mais tranquila e confiante. Conseguindo com que os alunos antes em dificuldade de querer aprender, permaneçam e envolvam-se nas atividades da aula com gosto. Tem-se a cada dia uma pequena conquista, porém com resultados positivos.

Observando as construções de Ausubel, o estudante precisa estar disposto a relacionarse com o material a ele apresentado. E estas ações exploraram diferentes situações (recreio, recreação, convívio com os demais colegas de escola) que exigiam do grupo uma posição de equipe e de identidade.

A turma tornou-se mais "solta", solicitando espaço para cantar, declamar poesias, dançar, inclusive produções próprias. Observou-se que os alunos perderam a vergonha do "achar feio", ou de receber críticas do colega por "não saber ainda", e sim valorizando as conquistas dos amigos.

A escola deve ser um espaço de vida, educar significando seus conhecimentos e também suas emoções e o trato de suas relações, excluindo o abismo entre razão e sentimentos, e de certa forma impondo ao sistema educativo a abertura de colocar no mesmo plano a importância da qualidade das relações e o compromisso com o saber.

A criança sendo estimulada para os estudos com confiança, carinho, responsabilidade, de forma prazerosa, positivamente corresponde aos incentivos, tarefa esta não só dos professores, mas de toda escola enquanto comunidade formadora, ou seja, funcionários e pais e/ou responsáveis também precisam exercer suas funções de forma consciente.

Assim, todos os envolvidos no contexto da educação, influenciam os demais, com suas experiências, vivências e saberes, como também dão seu próprio significado ao entendimento de novos conhecimentos.

O desafio de tornar a escola um lugar de motivação é diário. Pouco adianta desenvolver uma aula criativa, com muitos recursos, se realizá-la de forma mecanizada ou automática, sem espaço para os questionamentos, a reflexão e o fazer pensar. Pode-se ter a melhor atividade, mas se não houve a compreensão, o significado que determina o interesse do aluno, pouco se terá em aprendizagem.

Logo, quando demonstrada em sala de aula, a afetividade vem ao encontro do benefício do desenvolvimento dos alunos, auxiliando na confiança e segurança durante o processo de aprendizagem. 


\section{Referências}

CHARLES, CM. Piaget ao alcance dos professores. Rio de Janeiro, RJ: Ao livro Técnico, 1983.

DELVAL, Juan. Crescer e Pensar: a construção do conhecimento na escola. Porto Alegre: Artes Médicas, 1998.

FERNANDES, Elisângela. David Ausubel e a aprendizagem significativa. Disponível em < http://revistaescola.abril.com.br> Acesso em 04 maio 2016.

GOULART, Íris Barbosa. Piaget: experiências básicas para utilização pelo professor. Petrópolis, RJ: Vozes, 1990.

JACQUIN, Guy. As grandes linhas da psicologia da criança. 11. ed. Rio de Janeiro, RJ: Record, 1985.

KAMII, Constance. A criança e o número. 29. ed. São Paulo: Papirus,2003.

MUSSEN, Paul H. O desenvolvimento psicológico da criança. 5. ed. Rio de Janeiro, RJ: Zahar Editores, 1970.

PARO, Vitor Henrique. Gestão Democrática da Escola Pública. São Paulo: Ed. Ática, 1997.

PIAGET, Biografia. Disponível em <www.biografias.netsaber.com.br> Acesso em 03 abr. 2007. . Disponível em <www.educ.fc.ul.pt> Acesso em 03 abr. 2007.

Disponível em <www.10emtudo.com.br> Acesso em 05 abr. 2007.

PIAGET, Jean; SZEMINSKA, Alina. A gênese do número na criança. 2. ed. Rio de Janeiro RJ: Zahar Editores, 1975.

PIAGET, Jean; INHELDER, Bärbel. O desenvolvimento das quantidades físicas na criança.

2. ed. Rio de Janeiro, RJ: Zahar Editores, 1975.

RANGEL, Ana Cristina. Educação matemática e a construção do número pela criança. Porto Alegre: Artes Médicas, 1996 
SEBER, Maria da Glória. Piaget: o diálogo com a criança e o desenvolvimento do raciocínio. São Paulo: Scipione,1997.

ZANLUCHI, Fernando Barroso. Desenvolvimento da criança de 7 a 12 anos. In: Universidade Norte do Paraná. Curso normal superior: habilitação para os anos iniciais do ensino fundamental: módulo IV. Londrina: Ed.UNOPAR, 2004.cap.3, p.51-72. 